THE KURUME MEDICAL JOURNAL Vol. 18, No. 4, 1971

\title{
PATHOLOGICAL STUDIES ON PRIMARY CARCINOMA OF THE LIVER
}

\section{A STUDY OF 89 CASES AMONG 3890 NECROPSIES AND A STUDY OF ALPHA-FETOPROTEIN IN THE SERUM OF 17 CASES.}

\author{
MASAMICHI KOJIRO \\ First Department of Pathology, Kurume University School \\ of Medicine, Kurume, Japan
}

(Received for publication September 28, 1971)

1. Eighty-nine primary liver cancers were noted among 3890 necropsies performed at Kurume University School of Medicine, in the period 19291971, a frequency of 2.28 per cent.

2 . The sex ratio of male to female was thus $7: 1$. The average age was $57.26 \pm 11.82$ years. The average age for male was $56.96 \pm 11.77$ years and for female 59.60土10.76 years. Agewise, the largest frequency was in the sixth decade in life.

3. General malaise was the most common as an initial symptom. Abdominal pain, ascites, enlargement of the liver, icterus, and fullsensation of the abdomen were prominent symptoms in the course of primary liver cancer. The average survival time was very short compared with other malignant tumors. About fifty per cent of patients died within three months after the appearance of initial symptoms.

4. Bleeding from digestive organs including esophageal varices and tumor, and hepetic coma were frequent as a cause of death.

5. Ascites was seen in 86 per cent and icterus was seen in 67.3 per cent of all cases. Association of liver cirrhosis somewhat effected liver and spleen weight.

6. Metastasis was relatively rare compared with other malignant tumors, a frequency of 59.6 per cent. The lungs were the most frequent recipients $(42.7 \%)$.

7. The gross classification of primary liver cancer was carried out as follows; nodular form, massive form, and diffuse form.

8. Histologically, the fifty-seven liver cell carcinomas were classified into trabecular, glandular, mixed type of trabecular and glandular, giant cell carcinoma, and small cell carcinoma. Seven cases of bile duct carcinoma and one case of combined carcinoma were observed.

9. Most frequent associted lesion was liver cirrhosis and most of associated liver cirrhosis were Miyake's B type. Gastroduodenal ulcer and gastric erosion were observed in 30.3 per cent of all cases. Thirteen of the 89 primary liver cancers were associated with schistosomiasis japonica, but no causal relationship could be histologically found.

10. Detection of alpha-fetoprotein was carried out in recent seventeen cases. Alpha-fetoprotein was positive in eleven cases but negative in six cases. No marked relationship between alpha-fetoprotein and histological findings could be found. 


\section{INTRODUCTION}

Pathologically, primary liver cancer was first recognized by Bayle and Cayol (1812). Morgagni saw various masses in the liver, but he did not clearly distinguished between true neoplasma and other mass-forming lesions, and certainly not between primary and metastatic tumors. Cruveilhier said that the most frequent and severe disease of the liver was carcinoma. However, he also did not clearly distinguish between primary and metastatic tumors, and his recognition depended upon gross appearance, so he might have overlooked small primary tumors in other organs. Rokitansky $^{41}$ ) also recognized great frequency of liver cancer and gave its numerical relation to carcinoma of other organs as one to five.

By the end of the nineteenth century many papers on liver tumors had been writen, and hundreds cases reported. Thus, Leichtenstein reviewed 358 secondary and 72 primary liver cancers reported from 1845 to 1872 . The earliest true liver cancer conceded by Hansemann 20) was one of ten cases reported in Freichs' series in 1861. A critical evaluation of the cases in the early papers is difficult because of the lack of pricise nomenclature, criteria for diagnosis, and the inadequate illustrations. The understanding of liver cancer had nevertheless been steadily advancing.

Hanot \& Gilbert ${ }^{21)}$ reviewed the gross classification of liver cancer and Kelsch \& Kiener ${ }^{26)}$ reported two cases in Algieria in 1876. In 1901, Eggel ${ }^{10}$ classified liver cancer into adenocarcinoma and carcinoma solidum. In 1911, Yamagiwa ${ }^{55)}$ first classified liver cancer histologically into "Hepatoma" arising from liver cell and "Cholangioma" ariaing from intrahepatic bile duct.

These terms, Hepatoma and cholangioma, have been used world wide.
Following Yamagiwa's work, Mori(1956) ${ }^{35)}$, Shikata (1959) ${ }^{44)}$, Miyaji (1960) ${ }^{33)}$ reported exellent studies of causal relations between liver cancer and liver cirrhosis in necropsies.

There are strinking differences in incidence of primary liver cancer in racial and geographical environments.

Primary liver cancer is relatively rare in Europe and North America, but frequent in South Africa, India, south east Asia, China, and Japan. Berman $(1929)^{5)}$, Geddes (1970) ${ }^{14)}$, Yamagiwa (1911) 55), Yamane (1918) 57) and Kika (1929) ${ }^{27)}$ reported on racial and geographical distribution.

In experimental studies of liver cancer, Sasaki and Yoshida $(1932)^{56)}$ opened the field of chemical hepatomagenesis by feeding o-aminoazotoluol to rats. Kinoshita (1937) also succeeded creating liver cancer by feeding $p$-dimethylaminoazobenzen to rats. Miyaji also reviewed experimental studies on liver cancer.

The chemical hepatomagens include chloroform, carbon tetrachloride, selenium, tannic acid, urethane, p-dimethylaminoazobenzen, 2-acetylaminofluorecene, thiourea, 1,2-benzanthracene, and many others.

Diagnostic techniques of primary liver cancer have been greatly advanced in recent years. The clinical usefulness of assaying alpha-fetoprotein in the serum of patients with primary liver cancer is now well documented. In 1956, Bergstrand ${ }^{16)}$ reported that alpha-fetoprotein was found as a normal constituent of fetal serum, but the levels are low at birth and fall rapidly subsequently. The only situations where alpha-fetoprotein has been in the serum of adult human are emblionic tumors of the ovary and testis and primary hepatocellular carcinoma of the liver.

The auther studied clinical and pathological findings in eighty-nine nec- 
ropsies of primary carcinoma of the liver in Kurume University School of Medicine, and examined alpha-fetoprotein in the serum of seventeen necropsies of primary liver cancer. The relationship between alpha-fetoprotein and histological findings of primary liver cancer was studied.

\section{MATERIAL AND METHOD}

For pathological study eighty-nine cases of primary liver cancer among 3890 necropsies performed at Department of Pathology, Kurume University School of Medicine from January, 1929 to June, 1971 were used. Specimens were obtained from three portions of the liver (tumor, normal, and border of tumor and normal) and fixed by ten per cent formalin solution and Hematoxilin-Eosin stain, Azan stain, and Van-Gieson stain were carried out.

For detection of alpha-fetoprotein the sera were obtained from recent cases with primary liver cancer. Antialpha-fetoproetin (Horse), was used as an antiserum, and detection of alphafetoprotein was performed using the Ouchterlony method.

\section{RESULTS}

\section{A. Frequency}

Eighty-nine cases of primary liver cancer (2.28\%) were seen among 3890 necropsies performed at Kurume University School of Medicine, in the period 1929-1971.

\section{B. Age and sex (Fig. 1)}

Seventy-eight cases were male and eleven female. The sex ratio of male to female was thus 7:1. Agewise, the largest frequency was in the sixth decade of life. The average age was $57.26 \pm 11.82$ years. The average age for male was $56.92 \pm 11.77$ years and for female $59.60 \pm$ 10.76 years.

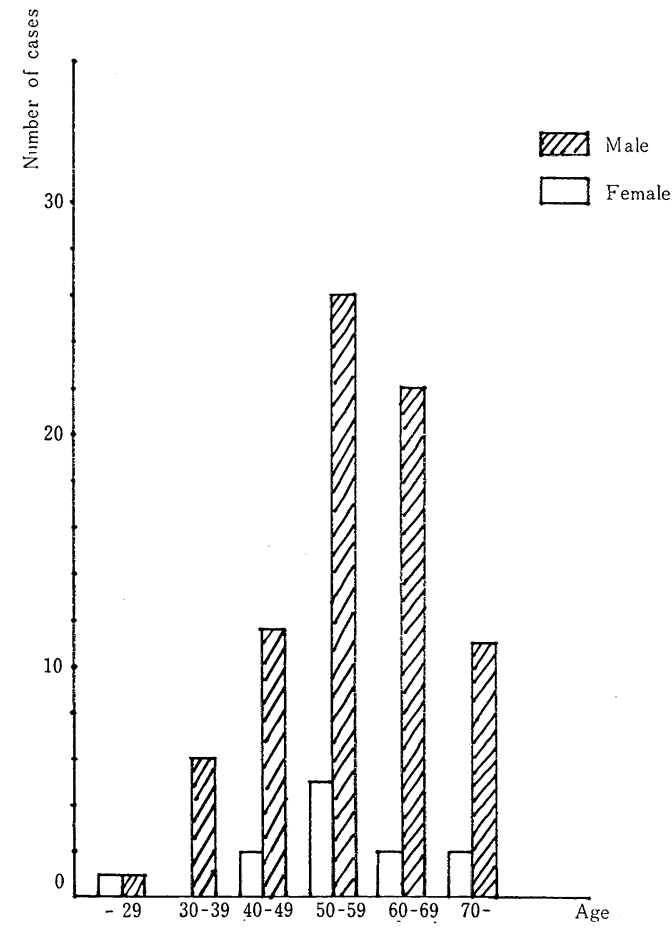

Fig. 1 Age distribution among the 89 liver cancers.

\section{Clinical symptoms}

Clinical symptoms and liver function tests were studied in thirty-three cases of primary liver cancer.

i ) Initial symptoms (Table 1)

General malaise was the most common complaint at the onset of primary liver cancer. Right upper-quadrant pain and loss of appetite were also frequent. However, enlargement of the liver, icterus, and ascites, suggesting primary liver cancer, were few.

ii) Main symptoms (Table 2)

Enlargement of the liver in the course of primary liver cancer was observed in thirty of the thirty-three liver cancers. Abdominal pain, icterus, and ascites were also frequently observed.

iii) Past history

Of the thirty-three liver cancers, ten cases were heavy drinkers, five 
TABLE 1

Initial Symptoms

\begin{tabular}{l|c}
\hline General malaise & 18 Cases \\
Upper quadrant pain & 13 \\
Loss of appetite & 8 \\
Enlargement of the liver & 7 \\
Fullsensation of the abdomen & 5 \\
Icterus & 3 \\
Ascites & 1 \\
Fever & 1 \\
\hline
\end{tabular}

TABLE 2

Main Symptoms

\begin{tabular}{l|l}
\hline Enlargement of the liver & 30 cases \\
Abdominal pain & 24 \\
Icterus & 20 \\
Fullsensation of the abdomen & 15 \\
Anemia & 13 \\
Vomiting & 4 \\
Diarrhea & 2 \\
Fever & 9 \\
Splenomegaly & 4 \\
\hline
\end{tabular}

cases had a history of hepatitis, and one case had a history of schistosomiasis japonica.

iv) The average survival time

Of the thirty-three liver cancers, fifteen died within three months, twelve died within 4-6 months, and six cases died within 7-11 months since the onset of liver cancer. No case survived over one year.

v) Liver function tests

Total bilirubin levels remarkably increased in thirty cases (90\%) among the thirty-three liver cancers. Alkalin-phosphotase and lactic-dehydrogenase levels also increased in twenty-three cases (70 $\%)$. S-GOT levels were abnormal in twenty-three cases (70\%), and most of them were over 100 units, while S-GPT levels were abnormal in only thirteen cases, and cases over 100 units were few. No relationship between transaminase and size of the tumor could be seen. Abnormality of gamma-globulin levels was dominant in cases with liver cirrhosis.

\section{Anatomical findings}

i ) Liver weight (Fig. 2)

In eighty per cent of seventy-nine liver cancers, liver weight ranged from $1500 \mathrm{~g}$ to $3000 \mathrm{~g}$. All cases weighing under $1000 \mathrm{~g}$ were associated with liver cirrhosis. Mean liver weight with liver cirrhosis was $2156.3 \mathrm{~g}$ and without liver cirrhosis $2670 \mathrm{~g}$.

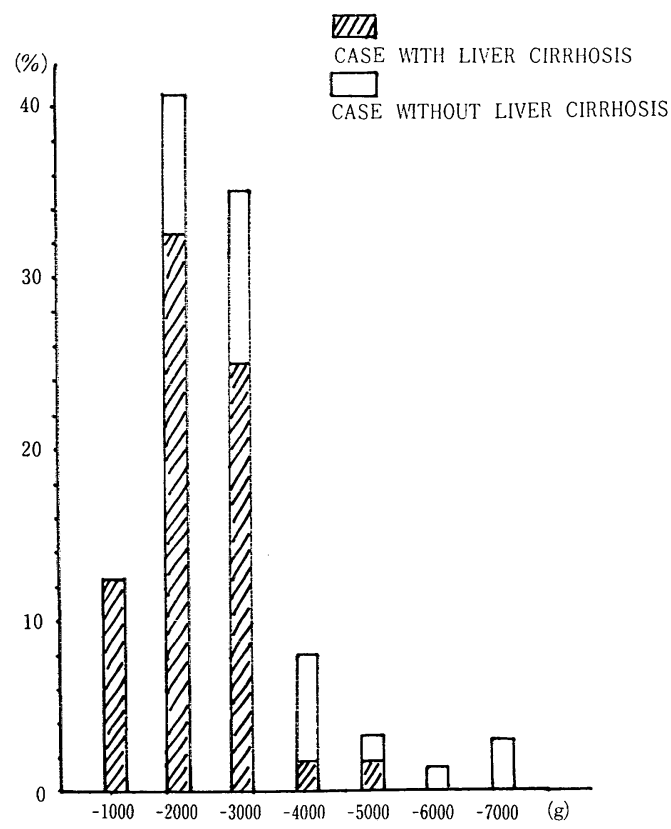

Fig. 2 Liver weight distribution among the 86 liver cancers.

ii) Spleen weight (Fig. 3)

In eighty-two per cent of eightynine liver cancers, spleen weight ranged from $100 \mathrm{~g}$ to $300 \mathrm{~g}$ and eighteen cases with liver cirrhosis were over $300 \mathrm{~g}$.

iii)Gross type of tumor

The gross type of primary liver cancer was classified into massive, nodular, and diffuse according to Eggel's classi- 


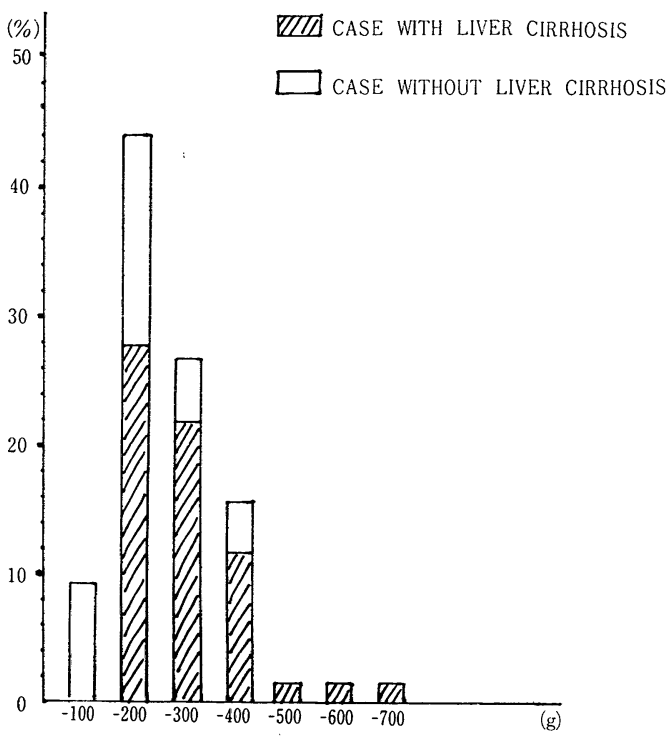

Fig. 3 Spleen weight distribution among the 79 liver cancers.

fication. Thirteen of the twenty-five liver cancers were nodular, ten massive, and two diffuse. iv) Location of tumor

Of the twenty-five cancers, thirteen were found in both right and left lobes, eleven in the right lobe, and one was seen in the hilum. No case was found in only left lobe.

v) Ascites (Fig. 4)

Ascites was observed in seventy-six of the 89 liver cancers, and 60 per cent of them were bloody. Amount of ascites ranged in most cases from $2000 \mathrm{ml}$ to $3000 \mathrm{ml}$, with a maximum of $10000 \mathrm{ml}$.

vi) Esophageal varices

Esophageal varices were found in twenty-five of the 89 liver cancers and all of them were associated with liver cirrhosis. Fatal bleeding from esophageal varices were seen in nine cases.

vii) Associated lesions

Fifty-two $(63.4 \%)$ of the eighty-two hepatocellular carcinomas were associated with liver cirrhosis, but only two $(28.5 \%)$ of the seven bile-duct carcinomas were associated with liver cirrhesis.

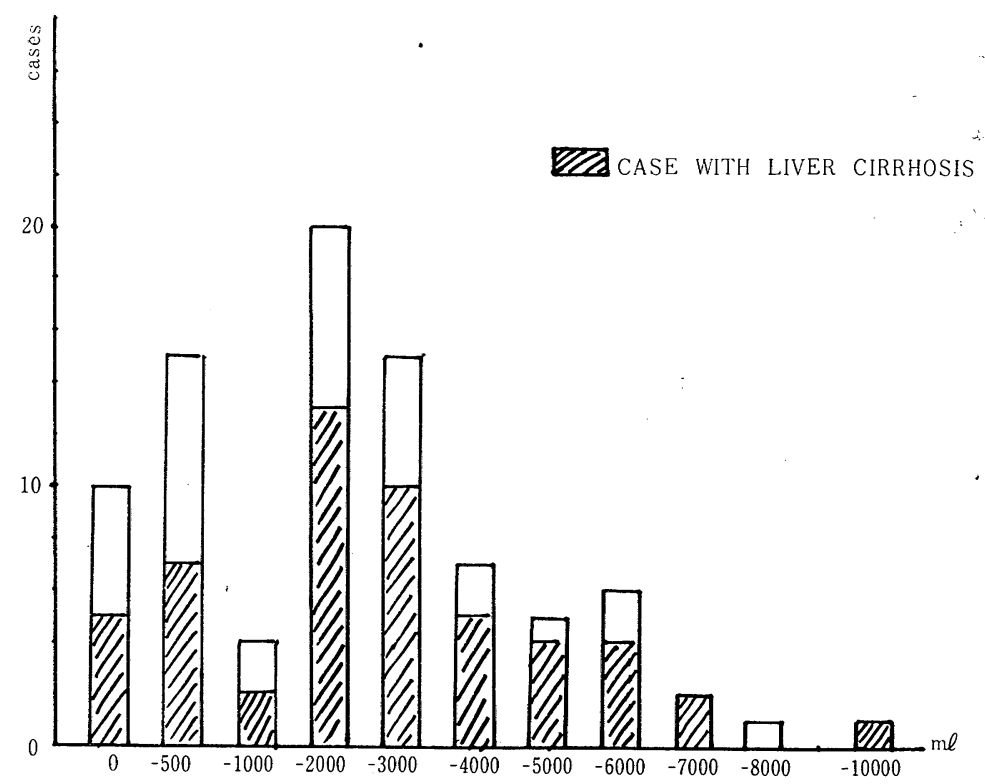

Fig. 4 Ascites among the 89 primary liver cancer. 
Type of associated liver cirrhosis was Miyake's B type in most cases. Thirteen of the eighty-nine liver cancers were associated with schistosomiasis japonica. Primary liver cancer was more frequent in cases with schistosomiasis japonica than in cases without it. However, no active findings suggesting causal relation between schistosomiasis japonica and primary liver cancer could be found. Gastro-duodenal ulcer and gastric erosion were observed in twenty-seven (30.3 $\%)$ of the eighty-nine liver cancers as shown in Table 3.

TABLE 3

Gastro-Duodenal Lesions Among the 89 Liver Cancers

\begin{tabular}{l|c|c}
\hline \multicolumn{1}{c|}{ Lesion } & Cases & Percentage \\
\hline Gastro-duodenal ulcer & 10 & 11.6 \\
Gastric erosion & 11 & 19.7 \\
\hline Total & 27 & 31.3 \\
\hline
\end{tabular}

viii) Metastasis

Extrahepatic metastases were found in thirty-three of the eighty-nine liver cancers. The lungs were the most frquent recipients, metastasis to the lungs was seen in thirty-eight (42.7\%) among the eighty-nine liver cancers. Metastases to the other organs were as follows; pancreas, $10.1 \%$; adrenal, $6.7 \%$; bone, $2.2 \%$; rectum, $2.2 \%$. Metastasis to the lymph nodes was found in twenty-seven $(30.3 \%)$. Direct infiltrations of liver cancer to the diaphragm, Douglas' cavity, and peritonium were observed in ten cases (Table 4).

\section{ix) Icterus}

Icterus was found in sixty of the eighty-nine liver cancers, and it was severe in thirty-six of them and they were associated with liver cirrhosis. Thirty-eight cases with icterus were associated with liver cirrhosis.
TABLE 4

The Sites of Metstasis

\begin{tabular}{l|r|r}
\hline \multicolumn{1}{c|}{ Organs } & Cases & Percentage \\
\hline Lungs & 38 & 42.7 \\
Pancreas & 9 & 10.1 \\
Adrenal & 6 & 6.7 \\
Bone & 2 & 2.2 \\
Thyroid & 1 & 1.1 \\
Stomach & 2 & 2.2 \\
Rectum & 2 & 2.2 \\
\hline Lymph node & 27 & 30.3 \\
\hline Portal & 15 & 16.8 \\
Mediastinal & 9 & 10.1 \\
Pancreatic & 7 & 7.8 \\
Aortic & 5 & 5.6 \\
Supraclavicular & 2 & 2.2 \\
Mesenteric & 1 & 1.1 \\
\hline Infiltration & 10 & 11.3 \\
\hline Diaphragm & 4 & 4.4 \\
Douglas' cavity & 3 & 3.3 \\
Gall blader & 3 & 3.3 \\
Kidneys & 1 & 1.1 \\
\hline & &
\end{tabular}

TABLE 5

Histological Classification of Primary Carcinoma of the Liver

\begin{tabular}{|c|c|c|}
\hline \multicolumn{2}{|c|}{ Liver cell carcinoma } & 57 cases \\
\hline \multirow{3}{*}{ mature } & trabecular & 46 \\
\hline & glandular & 3 \\
\hline & $\begin{array}{c}\text { mixed type of trabecular } \\
\text { and glandular }\end{array}$ & 4 \\
\hline \multirow{2}{*}{ immature } & giant cell carcinoma & 4 \\
\hline & small cell carcinoma & 0 \\
\hline \multicolumn{2}{|c|}{ Bile duct carcinoma } & 7 cases \\
\hline \multicolumn{2}{|c|}{ Combined type } & 1 cases \\
\hline \multicolumn{2}{|r|}{ Total } & 65 cases \\
\hline
\end{tabular}

\section{E. Histopathology (Table 5)}

Sixty-five cases, which could be histologically examined, were classified into as follows ; 
1. Liver cell carcinoma (Hepatoma)

a. Mature type

i) Trabecular liver cell carcinoma

The cells show a marked resembrance to normal liver cells, and show a trabecular arrangement, which is two to several cells in width. The trabeculae are covered by a thin membrane having endothelial cells and various sized cell islets are observed. Small islet is composed by about ten cells and large islets is composed by 20-30 or more cells. Small and large islets usually coexist in most cases. Appearance of giant cell and glandular pattern is often observed. In my series, forty-six of the fifty-eight liver cell carcinomas were trabecular type.

ii) Glandular liver cell carcinoma

Tumor cells turn to columnar epithelium and form glandular pattern. Sometimes, it is difficult to distinguish between this type and bile duct carcinoma. Four cases of this type were found in the present series.

iii) Mixed type of trabecular and glandular

This type shows both trabecular and glandular patterns. Four cases of this type were observed in the present series.

b) Immature type

i ) Giant cell carcinoma

Tumor cells show loose arrangement and marked giant cells are observed. Four cases of giant cell carcinnma were observed in the present series.

ii) Small cell carcinoma

This type is mainly composed by small cells smilar to lymphocyte and shows medullary pattern sometimes. This carcinoma was not observed in the present series.

2. Bile duct carcinoma (Cholangioma)

Bile duct carcinoma arises from the intrahepatic bile duct. Columnar or cuboidal epithelium forms glandular pattern, and cystic dilation and papillary proliferation are often seen. Mucous formation is common and proliferation of connective tissue is obviously observed in most cases. Seven bile duct carcinomas were found in the present series.

3. Combined type of liver cell carcinoma and bile duct carcinoma. Only one case was found in the present series.

$F$. Serum alpha-fetoprotein in primary liver cancer

Serum alpha-fetoprotein was detected in recent seventeen autopsied cases of primary liver cancer, and comparative study between alpha-fetoprotein and histological findings was carried out. Alpha-fetoprotein was positive in eleven cases $(64.7 \%)$ among the seventeen primary liver cancers, but negative in six cases. Alpha-fetoprotein was negative in all metastatic liver cancer, gastric cancer, lung cancer, and liver cirrhosis. Histologically, ten of the eleven positive cases were mature liver cell carcinoma (Grade II of Edmonson's classification) and one was immature giant cell carcinoma (Grade III of Edmonson's classification). Among the six negatrve cases, four cases were mature trabecular liver cell carcinoma and one of the four negative cases was macroscopically typical so-called green hepatoma. Two of the six negative cases were immature liver cell carcinoma (Grade III and Grade IV of Edmonson's classification). Although cases were not enough in number, no marked relationship between alpha-fetoprotein and histological findings could be obtained. No relationship between alpha-fetoprotein and size of tumor was also found (Table 6).

\section{DISCUSSION}

\section{Pathogenicity}

Although certain pathogenicity of primary liver cancer is still unknown, it has indicated the importance of the corelation between primary liver cancer and liver cirrhosis 5) 9) 23) 33) 35) 44). It also calls attention to the relationship 
TABLE 6

Alpha-Fetoprotein in Primary Liver Cancer

\begin{tabular}{c|c|c|c|c|c|c}
\hline No. & Age \& Sex & $\alpha$-Feto. & Liver weight & Size of tumor & Histology & Liver cirrhosis \\
3285 & $73, \mathrm{M}$ & - & $2350 \mathrm{~g}$ & $60 \%$ & trabecular & - \\
3333 & $51, \mathrm{M}$ & + & $2150 \mathrm{~g}$ & $40 \%$ & trabecular+grandular & + \\
3589 & $62, \mathrm{M}$ & + & $2380 \mathrm{~g}$ & $60 \%$ & trabecular & (fibrosis) \\
3631 & $55, \mathrm{~F}$ & + & $2300 \mathrm{~g}$ & $80 \%$ & " & + \\
3638 & $65, \mathrm{M}$ & + & $950 \mathrm{~g}$ & $20 \sim 30 \%$ & " & + \\
3645 & $70, \mathrm{M}$ & + & $1450 \mathrm{~g}$ & $60 \sim 70 \%$ & " & + \\
3669 & $51, \mathrm{M}$ & + & $2600 \mathrm{~g}$ & $80 \%$ & " & + \\
3707 & $28, \mathrm{M}$ & + & $4400 \mathrm{~g}$ & $60 \sim 70 \%$ & " & + \\
3718 & $60, \mathrm{M}$ & - & $2490 \mathrm{~g}$ & $60 \%$ & immature giant cell car. & + \\
3731 & $51, \mathrm{M}$ & + & $2020 \mathrm{~g}$ & $70 \sim 80 \%$ & immature giant cell car. & + \\
3774 & $77, \mathrm{M}$ & + & $1800 \mathrm{~g}$ & $60 \%$ & trabecular & + \\
3799 & $60, \mathrm{M}$ & - & $1100 \mathrm{~g}$ & $50 \%$ & " & + \\
3822 & $44, \mathrm{M}$ & + & $1950 \mathrm{~g}$ & $40 \sim 50 \%$ & " & + \\
3868 & $47, \mathrm{M}$ & - & $1550 \mathrm{~g}$ & $70 \%$ & combined carcinoma & + \\
3890 & $56, \mathrm{M}$ & - & $2120 \mathrm{~g}$ & $50 \%$ & trabecular & + \\
3914 & $70, \mathrm{M}$ & - & $950 \mathrm{~g}$ & $30 \sim 40 \%$ & " \\
3932 & $70, \mathrm{M}$ & + & $2360 \mathrm{~g}$ & $60 \%$ & " \\
\hline
\end{tabular}

between primary liver cancer and hepatic lesions due to chronic parasitism ${ }^{4}$ ) 23) 24) 27) 48) 49), toxication ${ }^{30)}$, nutrition disorder ${ }^{4)}$, alcoholic disorder ${ }^{4)}$, and hepatitis $^{4)}$ 51) 54). Higginson ${ }^{15)}$ presumed that stimulation due to hepatitis virus effected to certain malnutrition condition and it might play a great role as an accelerator of primary liver cancer.

Geographical, racial, and sexual differences of the incidence may be able to settle pathogenicity of primary liver cancer.

Recently, pathogenicity of primary liver cancer has been investigated by study of serum alpha-fetoprotein and Australia antigen. These immunological studies are very relevant to studies of primary liver cancer.

\section{Frequency}

The incidence of primary liver cancer in Europe and North America is nothing but $0.11-0.50$ per cent of all necropsies, as reported by Edmonson \&
Steiner ${ }^{9)}$. In Japan, it comprises 0.842.21 per cent of all necropsies and 13.9 per cent of all malignant tumors. The incidence of primary liver cancer in necropsies in Japanease reports varies as follows ; $2.28 \%$, Yamane ${ }^{57)}$; $0.84 \%$, Kika 27) ; $2.21 \%$, Mori ${ }^{35)}$; $1.75 \%$, Miyaji ${ }^{33)}$; In the present report, it was $2.26 \%$. The incidence of primary liver cancer in Japan is much higher than in Europe and North America. In general, it can be said that the incidence of primary liver cancer in Asia including Japan and Africa is extremely high.

\section{Sex and age}

Primary liver cancer occurs at all ages, from infancy to old age. Edmonson 9) reported that where frequency is low, as in Europe and North America, the average age is in the sixth decade, as in many other carcinomas; while in population where the frequency is higher, the average age is lower. In Japan, Miyaji ${ }^{33)}$ reported that primary liver 
cancer is the most frequent in the sixth decade, the fifth decade being second in frequency. Thus, it confirms Edmonson's claim - primary liver cancer in preditection area such as Asia and Africa occurs at an earlier age than in Europe and North America. In the present study, primary liver cancer was most frequent in the sixth decade, with the seventh decade next, with little difference compared to reports from Europe and North America. Primary liver cancer is remarkably more common in male than in female, as seen in many reports ${ }^{9)}$ 27) 33) 35) 44) 50) 57). In this study, the sex ratio was thus $7: 1$, slightly higher than in other reports.

\section{Clinical symptoms}

i ) Initial symptoms

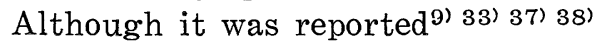
50) that abdominal pain was by far the most common complaint at the onset of liver cancer, in the present series, general malaise was the most frequent (52.0\%) and abdominal pain (right upperquadrant pain or epigastralgia) next. Enlargement of the liver, icterus, and ascites suggesting liver cancer were rarely seen. Symptoms which are rather noticed in other diseases (disorder of the stomach or gall bladder, and liver cirrhosis) were by far more common. .

ii) Main symptoms

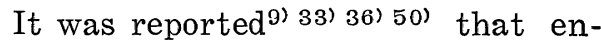
largement of the liver was the most common in the course of liver cancer and abdominal pain, icterus, and abdominal swelling next. Quite the same data were also obtained in this study. These symptoms appear at relatively terminal stage because of abundant compensation of the liver.

\section{Liver function tests}

The tests, which examine the normal functions of the liver, were valuable to examine lesions spreading over the liver as hepatitis and liver cirrhosis. Those tests were useless for early diagnosis of localized lesions such as liver cancer due to the extremely strong compensation of the liver.

The developed biochemical examinations, including that of alkaline-phospotase, have come to play a significant role in diagnosis of liver cancer. Although it was reported in many studies ${ }^{21)}{ }^{25}$ ) 36) 37) 38) 54) that abnomality of alkalinephosphotase was recognized in 70-90 per cent of liver cancer, other reporters stated that no tendency toward abnomality of alkaline-phosphotase was found. In the present series, abnomality of alkaline-phosphotase was seen in 80 per cent among 33 cases.

Transaminase : it is commonly held 21) 25) 32) 36) 37) 38) 54) that transaminase generally shows GOT $<$ GPT pattern in hepatitis and GOT $>$ GPT pattern in liver cancer. In the present series, this pattern of transaminase was observed quite markedly.

Lactic dehydrogenase (LDH) : it is held ${ }^{2132(36) 37(38) 54}$ that lactic dehydrogenase markedly increase in primary liver cancer, metastatic liver cancer, lung cancer, and leukemia. Increase of $\mathrm{LDH}$ was observed in about 76 per cent of my 33 cases.

Total protein : although it is reported that no remarkable decrease of total protein is found in liver cancer, decrease of total protein (under $6.5 \mathrm{~g} / \mathrm{dl}$ ) was seen in 44.8 per cent of my 33 cases.

Gamma - globulin : Momose ${ }^{32)}$ reported increase of $\gamma$-globulin was seen in nineteen of twenty-four liver cancers. Iwata ${ }^{25)}$ stated that $\gamma$-globulin fraction increased in liver cancer following liver cirrhosis according to effects of liver cirrhosis. Increase of $\gamma$-globulin was recognized in about 70 per cent of my 33 liver cancers, and all cases with increase of $\gamma$-globulin were associated with liver cirrhosis, No increase of $\gamma$-globulin was observed in most cases, which were associated with no liver cirrhosis. It can be 
said that increase of $\gamma$-globulin depends upon associated liver cirrhosis.

\section{Average survival time}

The average survival time after the appearance of initial symptoms is very short compared with other malignant tumors. Tull ${ }^{58)}$ reported that most cases died within a couple of months after the appearance of initial symptoms. Edmonson $^{\text {9) }}$ stated that the average survival time was forteen weeks in his cases. On mortality rate within six months, it was reported as follows ; $62 \%$ by Mori 35) ; $90 \%$ by Ueda ${ }^{53)}$; $76 \%$ by Miyaji ${ }^{33)}$ ; $92 \%$ by Shanmugaratnam, and it was $82 \%$ in the present series. This short survival time may be due to the fact that liver cancer may damage liver functions before the appearance of the initial symptoms, because of extremely abundant compensation of the liver.

\section{Anatomical findings}

a) Gross findings and location of tumor

Hanot \& Gilbert ${ }^{21}$ ) classified liver cancer into ; 1) cancer massiv, 2) cancer nodulaire, 3) cancer avec cirrhose, microscopically. Eggel's ${ }^{10}$ classification (used world-wide) divided liver cancer into nodular form, massive form, and diffuse form. Eggel's classification was used in this study. It was reported ${ }^{9)}{ }^{33}$ ) 50) that nodular form was the most common, massive form next, and diffuse the least frequent. In the present series, nodular form was observed in $52.2 \%$ of all cases, massive form in $41 \%$, and diffuse form in $6.8 \%$. In several cases it was difficult to distinguish between nodular and massive.

Location of tumor; Liu stated that 95 per cent of liver cancer were seen in the right lobe. Miyaji ${ }^{33)}$ reported that $49.9 \%$ were in all lobes and $40 \%$ were in the right lobe, $2.3 \%$ were in the hilum, and no case was seen only in the left lobe. Miyaji stated that differences of the left and right lobe in tumor location may have been caused by differeces of weights of the left and right lobe. No relation between each form and association of liver cirrhosis was seen in this study.

b) Liver weight

Enlargement of the liver is very frequently found. The reported means of liver weight of autopsied liver cancer were as follows ; $2950 \mathrm{~g}$ by Tull ${ }^{58)} ; 3653$ $\mathrm{g}$ by Schupbach ${ }^{46)}$. In my series, liver weight ranged from $670 \mathrm{~g}$ to $6400 \mathrm{~g}$, and 85 per cent of all cases ranged from 1500 $\mathrm{g}$ to $3000 \mathrm{~g}$. Relationship between liver weight and association of liver cirrhosis could be somewhat considered. All cases weighing under $1000 \mathrm{~g}$ were associated with liver cirrhosis.

c) Spleen weight

It is relatively rare that the spleen can be clinically palpable in patients with liver cancer. Hoyne ${ }^{16}$ reported that the spleen was clinically palpable in only six cases among the thirty-one liver cancers, but the spleen weighed over $300 \mathrm{~g}$ in eighteen among the thirtyone liver cancers in necropsy. In my series, 82 per cent of all cases ranged from $100 \mathrm{~g}$ to $300 \mathrm{~g}$. It can be said that rate of association of liver cirrhosis tends to be higher with increase of spleen weight. Therefor, weight of the spleen may be also effected by association of liver cirrhosis.

d) Ascites

Many reporters ${ }^{13)}$ 33) 50) stated that ascites was seen in high frequency among the patients with liver cancer. In my series, ascites was seen in 76 (88 $\%)$ among the 89 liver cancers and amount of ascites ranged from $2000 \mathrm{ml}$ to $3000 \mathrm{ml}$ in most cases, and 60 per cent were bloody. It can be said that bloody ascites is characteristic finding in primary liver cancer.

e) Icterus

Eggel \& Green ${ }^{10}$ reported that icwas seen terus in about 60 per cent of li- 
ver cancers. In my series, icterus was seen in sixty among the eighty-nine liver cancers and thirty-five of them were associated with liver cirrhosis. Generally icterus appears in a relatively late stage in the course of liver cancer, and it can be said that appearance of icterus signifies the terminal stage.

f) Esophageal varices

Esophageal varices are seen in high frequency among cases with primary liver cancer with liver cirrhosis. In my series, varices were observed in twenty five among the eighty-nine liver cancers and all of them were associated with liver cirrhosis. Nine cases died of fatal bleeding from varices. Although Edmonson ${ }^{9}$ reported that fatal bleeding from esophageal varces was seen in 16.6 per cent of primary liver cancers, Berman $^{5)}$ reported extremely low frequency of it-two cases $(2.6 \%)$ of 75 liver cancers.

Fatal bleeding from digestive organs including esophageal varices are relatively frequent. It was observed in 11.7 per cent by Sanford ${ }^{45}$ and 29 per cent by Schupbach \& Chappel ${ }^{46)}$. It can thus concluded that bleeding from esophageal varices, digestive organs, and tumor are relatively frequent as a cause of death of primary liver cancer.

g) Associated lesions

Lesions of the stomach or duodenum are relatively frequent in primary liver cancer ${ }^{50}$. In my series, ten cases of gastroduodenal ulcer and seventeen cases of gastric erosion were seen among the eighty-nine liver cancers. It is suggested that these gastroduodenal lesions may be caused by disorder of portal circulation.

Since the basin of the Chikugo river is the endenmic area of schistosomiasis japonica, association of schistosomiasis japonica is relatively frequent. Kameda 24) stated that schistosomiasis japonica was seen in fifty-six among the sixtyone liver cancers in necropsy and biopsy, and close relation between liver cancer and schistosomiasis japonica was thus recognized. Tsutsumi and Ozasa ${ }^{48)}$ 49) also studied the corelation between liver cancer and schistosomiasis japonica histologically, but no definite corelation could be obtained. In my series, primary liver cancer is more frequent in cases with schistosomiasis japonica, compared with cases without schistosomiasis japonica. Although these findings cannot confirm a direct causal relationship between schistosomiasis japonica and primary liver cancer, it is presumed that lesions of the liver in schistosomiasis japonica may be somewhat related to pathogenicity of liver cancer.

h) Metastasis

It is said that metastasis of liver cancer is markedly fewer than that of gastric cancer and other malignant tumors. Edmonson ${ }^{9)}$ reported that metastases were seen in thirty-six $(48 \%)$ of the seventy-five hepatocellular carcinomas, and occured more often and were more widespread in the more embryonal tumors (Edmonson's Grades III and IV). Rate of metastases in different studies are as follows ; $66 \%$ by Eggel ${ }^{10)} ; 70 \%$ by Mori $^{35)} ; 74.4 \%$ by Miyaji ${ }^{33)}$. In the present series, metastases were seen in fifty-three $(59.6 \%)$ of eighty-nine liver cancers. It was reported in many studies 8) 9) 28) 33) 50) that the lungs and regional lymph nodes were the most frequent recipients. It was also said that a substantial differences of metastasis was seen between hepatocellular carcinoma and bile duct carcinoma ; it was common that metastasis of hepatocellular carcinoma was haematogenous and that of bile duct carcinoma was lymphgenous.

In my series, metastasis to the lymph nodes was seen in 30.2 per cent. Mori 35) studied relationship between histological findings and metastasis of liver cancer, and attached importance to liver cirrhosis and a stromal conponent. 


\section{Histological classification and findings}

Primary liver cancer is classified into liver cell carcinoma arising from liver cells, bile duct carcinoma arising from bile duct cells, and mixed type of the two. Although primary liver cancer was considered as primary adenoma according to their histological findings by Kelsch \& Kiener ${ }^{26)}$, Henkelom ${ }^{17)}$ considered them malignant tumors because of extensive portal vein permeation. Eggel ${ }^{10)}$ classified primary liver cancer into carcinoma solidum and carcinoma adenomatosum. Goldzieher ${ }^{11}$ classified primary liver cell cancer into trabecular, medular, and alveolare, and classified bile duct carcinoma into basophilic, adenocarcinoma, and carcinoma simplex. Edmonson \& Steiner ${ }^{9)}$ classified liver cancer into liver cell carcinoma with trabecular structure and giant cell carcinoma without trabecular structure, and classified liver cell carcinoma showing trabecular structure into mature type and immature type. They also classified bile duct carcinoma into simple bile duct carcinoma and hilar carcinoma. Furtheremore, they given combined or multiple primary cancers a separate name and place in the classification. They also considered grade of malignany of liver cell carcinoma as follows ; relatively benign tumor, which can be regarded as adenoma, as I Grade, mature type as II Grade, and immature or embryonal type as III or IV Grade.

Mori ${ }^{35)}$ classified liver cancer in point of metastais and attached importance to a stromal conponent more than the tumor cells. The auther classified liver cell carcinoma into liver cell carcinoma bile duct carcinoma, and combined type according to Miyaji's classificaton ${ }^{33}$ ). It is relatively frequent that histological patterns of liver cancer are partially different in even same case. Trabecular liver cell carcinoma showed simple his- tological findings in most cases. However, glandular liver cell carcinoma was associated with other histological patterns (mostly trabecular) in most cases. so the auther gave combined type of glandular and trabecular liver cell carcinoma a seperate name and place in the classification. Appearance of giant cells, which may have been caused of degeneration of tumor cell, was frequently seen in trabecular liver cell carcinoma, but were relatively rare in immature liver cancer. Occasionally, some of liver cell carcinoma show extensive proliferation of connective tissue. Degeneration and necrosis of tumor tissue are seen in most cases and fat degeneration, bleeding, localized appearance of bile pigment or bile thrombus, and intensive cell infiltration are also frequently observed. Toyonaga ${ }^{50}$ reported that intensive cell infiltration in Glisson's capsule have been caused of spread of cholangitis due to obstruction of the bile ducts, and cell infiltration in necrotic area due to tumor thrombus in the branches of the portal vein have been caused of decreased resistance following circulation disturbance of the portal vein.

\section{Liver cirrhosis}

Importance of relationship between primary liver cancer and liver cirrhosis has been recognized world wide. Furthermore, it is significant that Miyake's $B$ type is most frequent in associated liver cirrhosis. Miyake and Mori ${ }^{31)}$ reporeted 86 cases of primary liver cancer among 390 cases of liver cirrhosis, and most of the 86 cases of liver cirrhosis with primary liver cancer were Nagayo's B type liver cirrhosis, which was composed by gathering of relatively large pseudolobules. They also confirmed that 48.6 per cent of Nagayo's B type liver cirrhosis were associated with primary liver cancer. Edmonson ${ }^{3)}$ reported that 89.2 per cent of liver cell carcinoma in 
his work were associated with liver cirrhosis. Miyaji ${ }^{29)}$ stated that 185 cases $(45.1 \%)$ of the 410 primary liver cancers were associated with liver cirrhosis, and 138 cases $(74.6 \%)$ of the 185 associated liver cirrhosis were portal or Laennec cirrhosis. Higginson ${ }^{15}$ ) reported that most of associated liver cirrhosis in Africa were postnecrotic type. Shikata reported that association of liver cirrhosis was seen in 7 cases of the 46 bile duct carcinomas. In the present series, association of liver cirrhosis was seen in 49 cases of the 79 liver cell carcinomas and in two cases of the seven bile duct carcinomas, and most of associated liver cirrhosis were Miyake's B type.

Relationship between primary liver cancer and liver cirrhosis is considered as follows ${ }^{53)}$;

1) Liver cirrhosis exists prior to liver cancer and causes of liver cancer.

2) Liver cancer exists prior to liver cirrhosis and causes of liver cirrhosis.

3) Liver cancer and liver cirrhosis have no any relational factors each other, and they occur independently.

4) Some same causal factor produces liver cancer on the one hand, and liver cirrhosis on the other hand. Although the presumption (1) has been supported by many investigators, it is still difficult to prove the process from nodular hyperplasia to adenoma, and then from adenoma to liver cancer. Nowadays, some investigators attach importance to possibility of the presumption(4). Kawasaki and Akagi in my department observed that liver cirrhosis occured prior to liver cancer in some of rats feeding $0.07 \%$ butter yellow, but liver cancer directly occured without liver cirrhosis in some of rats feeding $0.04 \%$ butter yellow. This experimental result gives support to the presumption-When the liver parenchyma is damaged by some toxic agent in long period, liver cirr- hosis occurs on the one hand and liver cancer occurs on the other hand. Steiner ${ }^{42)}$ reported that incidence of liver cancer is higher than that of liver cirrhosis in Africa, and liver cirrhosis in native African is fewer than in European living in Africa, in spite of that liver cancer in the former is more frequent than in the latter.

It is still difficult to confirm the complex developmental mechanism of primary liver cancer in nowadays.

\section{Alpha-fetoprotein}

In 1944, Pederson ${ }^{40}$ reported that fetal calf serum contained alpha-1-fetoglobulin, which was not seen in adult bovin serum. In 1956, Bergstrand ${ }^{6)}$ reported that electropholetic mobility of this serum fetoprotein in human fetus was that of an alpha-globulin, the protein migrating somewhat slower than serum albumin, but faster than the serum alpha-1-globulin.

Since Abelev and Tatarinov ${ }^{1 / 2)}{ }^{2}$ 2) reported the presence of alpha-fetoprotein in the serum of patients with primary liver cancer, many investigators took a serious view of alpha-fetoprotein. High positive rate of alpha-fetoprotein (60-90\%) in patients with primary liver cancer has been reported by many investigators ${ }^{1)}$ 3) 22) 34).

Nowadays, detection of serum alphafetoprotein has become crucial for reaching a definite diagnosis of primary liver cancer. Furthermore, estimation of alpha-fetoprotein in the course of primary liver cancer is available for follow up the effects of treatment.

Generally, alpha-fetoprotein tends to be positive in mature liver cell carcinoma (Grade II of Edmonson's classification), and negative in immature liver cell carcinoma (Grade III and IV of Edmonson's classification) and bile duct carcinoma. No marked differences of histological findings between alpha- 
fetoprotein positive and negative could be found, yet.

\section{ACKNOWLEGEMENT}

I am grateful for my director, Prof. Toshiro Nakashima, M. D. at the First Department of Pathology, Kurume University School of Medicine, who kindly gave me guidance and advice. And I also thank Assist. Prof. Hiroshi Tsutsumi, M. D. and Toshiyuki Ozasa, M. D. at the First Department of Pathology, Kurume University School of Medicine, who gave me kind guidances.

\section{REFERENCES}

1) Abelev, G. I. : Production of embryonal serum $\alpha$-globulin by hepatomas; review of experimental and clinical data. Cancer Res. 28, 1344-1350, 1968.

2) Abelev, G. I. et al. : Embryonal serum $\alpha$ globulin in cancer patients. diagnostic value, Int. J. Cancer, 2, 551-558, 1967.

3) AlPERT, M. E. et all. : $\alpha$-fetoglobulin in the diagnosis of human hepatoma. New Engl. J. Med., 278, 943, 1968.

4) Arima, M. : Epidemiological study of Primary carcinoma of the liver. Jap. J. Clin. 26 (8), 1833-1838, 1968. (In Japanease)

5 ) Berman, C. : Primary Carcinoma of the Liver ; a Study in Incidence, Clinical Manifestations, Pathology and Aetiology. London. H. K. Lewis \& Co. Ltd. 1951.

6 ) Bergstrand, C. G. : Demonstration of a new protein fraction in serum from the human fetus. Scand. J. Clin. Lab. Invest, 8, 174, 1956.

7 ) Charache, H. : Primary carcinoma of the liver; report of a case and review of the literature. Am. J. Surg., 43, 96, 1939.

8 ) Chester, K. J. : Primary hepatic cancer ; review of ninety-six cases. Arch. Intern. Med., 113 (1), 46-53, 1928.

9) Edmonson, H. A. A. \& Steiner, P. E. : Primary carcinoma of the liver, a study of 100 cases among 48900 necropsies. Cancer, 7, 462, 1954.

10) EGGEL, H. : Ueber das primäre Carcinom der Leber. Beitr. z. path. Anat. u. z. allg. Path., 30, 506-604, 1901.

11) Goldziener, M. and Bókay, Z. V. : Der primäre Leberkrebs. Virchows Arch. f. path. Anat., 203, 75-131, 1911.

12) Green, J. M. : Primary carcinoma of the liver; a ten years collective review. Int. Abstr. Surg., 69, 231, 1939.

13) Gustafson, E. G. : An analysis of 62 cases of primary carcinoma of the liver based on 24,400 necropsies at Bellevue Hospital. Ann. Int. Med., 11, 889, 1937.

14) Geddes, E. W. : Malignant hepatoma in the Bantu. Cancer, 25, 1271-1278, 1970.

15) Higginson, J. : The geographical pathology of primary liver cancer. Cancer Res., 23, $1624,1963$.

16) Hoyne, R. M. and Kernohan, J. W. : Primary carcinoma of the liver, a study of 31 cases. Arch. Int. Med., 79, 532, 1947.

17) Heukelom, S. : Das Adenokarzinom der Leber mit Cirrhose. Beitr. Z. path. Anat. u. z. allg. Path., 16, 341-387, 1894.

18) Ha jima, T. et al. : Clinical study on Primary carcinoma of the liver. Jap. J. Gastroent., 65 (12), 1353, 1968. (In Japanease)

19) Hattori, T. et al. : Biochemical diagnosis of primary carcinoma of the liver. Jap. J. Clin., 25 (10), 2294-2300, 1967. (In Japanease)

20) Hansemann, D. : Ueber den primären Krebs der Leber. Berl. klin. Wchnschr., 27, 353-356, 1890.

21) Hanot, V., \& Gilbert, A. : Étude sur les maladies du foie. Paris, Asselin \& Houzeau. 1888.

22) Houtek, J. et al. : Hepatocellular carcinoma in association with specific fetal $\alpha_{1}$ globulin, fetoprotein. J. pediat., 72, 186193, 1968.

23) Inoue, M. et al. : Clinical observation of chronic schistosomiasis japonica. Acta hepat. jap., 10 (5), 437-440, 1969. (In Japanease)

24) KAmEdA, H. et al. : Primary carcinoma of the liver in chronic schistosomiasis japonica. Jap. J. intern. Med, 27, 4, 761766, 1971. (in Japanese)

25) Iwata, S. et al. : Clinical observation of primary carcinoma of the liver and metastatic carcinomas. Jap. J. Gastroent, 65, 2, 1356, 1968. (in Japanese)

26) Kelsch, A. and Kiener, P. L. : Contribution à I' histoire de I' adénome du foie. Arch. Int. Med, 8, 622-656, 1876.

27) KıкA, G. : Statistische Studien über 110 
Fälle von primärem Leberkarzinom, welche im Pathologischen Institut der Kaiserlichen Universität zu Tokio seziert wurden; zugleich ein Beitrag zur Entwicklung der Kollateralbahn. Gann, 23 : $107-113,1932$.

28) Karsner, H. : A clinicopathological study of primary carcinoma of the liver. Arch. intern. Med., 8, 238, 1911.

29) Miya Ji, T. : Hepatoma in Japanease : relationship with liver cirrhosis. J. Jap. med. Ass., 54, 1137, 1965. (In Japanease)

30) Mryake, J. \& Okudaira, M. : Recent knowledges in hepatoma. Dag Diagn. Ther. (Osaka), 20, 9, 1573-1579, 1967. (In Ja panease)

31) Miyake, J. and Mori, W. : Primary carcinoma of the liver and liver carcinoma in Japan. Clin. all-round (Osaka), 10, 33, 1961.: (In Japanease)

32) Momose, G. et al. : Study of primary carcinoma of the liver. Jap. J. Gastroent, 65 (12), 1354, 1968. (In Japanease)

33) Mtyaji, T. : Pathological studies on hepatoma in recent ten year's. Acta hepat. jap., 1, 1, 17-36, 1960. (In Japanease)

34) Masopust, J. et al. : Occurrence bf fetoprotein on patients with neoplasms and non-neoplastic diseases. Int. J. Cancer, 3, 364-373, 1963.

35) MoRI, W. : A study of the metastasis of hepatoma. Tr. Soc. path. Jap., 45, 2, 224-236, 1956.

36) Nishikawa, T. : Clinicopathological studies on Cirrhosis and Primary Carcinoma of the liver. J. Wakayama med. Soc., 17(3), 449-470, 1966. (In Japanease)

37) Nakayama, J. et al. : Observation of primary carcinoma of the liver in necropsy for ten years. Jap. J. Gastroent., 63(9), 1076, 1966. (In Japanease)

38) Osajima, S. et al. : Clinical study of primary carcinoma of the liver for this six years. Jap. J. Gastroent., 65 (12), 1355, 1968. (In Japanease)

39) Onoda, T. et al. : Schistosomiasis japonica with primary carcinoma of the liver. J. Jap. Soc. intern. Med, 46(9), 1197, 1971. (In Japanease)

40) Pederson, K. O. : Fetuin, a new globulin isolated from serum. Nature, 154, 757, 1944.

41) Rokitansky, C. : A Manual of Pathologi- cal Anatomy, Vol. II. Philadelphia. Blanchard \& Lea, 1855.

42) Steiner, P. E. : Cancer ; race and geography. Some etiological, enviromental, ethnological, epidemiological, and statistical aspects in Caucadoids, Mongoloids, Negloids, and Mexicans. Williams and wilkins, Baltimore, 1954.

43) Strong, G. F. : Primary carcinoma of the liver-25 year study. Ann. Int. Med., 30, 791-798, 1949.

44) Shikata, T. : Studies on the relationship between hepatic cancer and liver cirrhosis. Acta path. jap., 9 (2), 267-311, 1959.

45) SANFORD, C, H. : Primary malignant disease of the liver. Ann. Int. Med., 37, 304-312, 1952.

46) Schupbach, H. J. and Chappel, R. B. : Primary carcinoma of the liver. A. M. A. Arch. Int. Med., 89, 436-444, 1952.

47) Shanmugaratnam, K. . Primary carcinoma of the liver and biliary tract. Brit. J. Cancer, 10, 232, 1956.

48) Tsutsumi, H. et al. : Relationship between cancer of the colon and the liver, and schistosomiasis japonica. J. Kurume med. Ass., 34 ( 3), 319-326, 1971. (In Jpanease)

49) Tsutsumi, H. et al. : Studies on liver fibrosis (cirrhosis) due to schistosomiasis japonica, Morphology of liver pert I. Kurume Med. J., 10 ( 1), 51-60, 1963.

50) Toyonaga, H. : Studies on primary hepatic carcinoma. J. Kurume med. Ass., 29 (10), 754-771, 1966. (In Japanease)

51) Tojo, Y. : From hepatitis to hepatic cancer. Therapeutics (Tokyo), 22 (3), 34-47, 1968. (In Japanease)

52) Tatarinov, Y. S. : Content of embryospecific-globulin in fetal and neonatal sera and sera from adult human with primary carcinoma of the liver. Vop. Med. Khim., 11, 20, 1966.

53) Winternitz, M. C. : Primary carcinoma of the liver. Johns Hopk. Hosp. Res., 17, 143, 1916.

54) YamagAtA, K. et al. : Clinical studies on malignant tumor of the liver. Jap. J. Gastroent., 65 (12), 1352, 1968. (In Japanease)

55) Yamagiwa, K. : Zur Kenntnis des primären parenchymatosen Leberkarzinoms ("Hepatoma"). Virchows Arch. f. path. Anat., 206, 437-467, 1911. 
56) Yoshida, T. : o-Amidoazotoluol ; Studien über die Entwicklung des experimentellen Hepatoms durch o-Amidoazotoluol, besonders die stufenweise Verfolgung der Leberverenderung bis zur Carcinomentstehung. Tr. Japan. Path. Soc., 24, 523530, 1934.

57) Yamane, S. : Statistical and Pathological studies on fifty-seven primary liver can- cers at Kyusyu University School of Medicine. Tr. Soc. Path. Jap., 8, 544, 1917. (In Japanease)

58) Tull, J. C. : Primary carcinoma of the liver : A study of 134 cases. J. Path. Bact., 35, 557, 1932.

59) Ueda, H. : Disease of the liver, II. Nankodo (Tokyo), 1965. (In Japanease)

\section{EXPLANATIONS OF PHOTOGRAPHS}

Photo 1. (No. 3799) Nodular type. Large greenish node arising in the right lobe. Liver weighing $1100 \mathrm{~g}$ in a 60 year-old man. $\alpha$ fetoprotein (-)

Photo 2. (No. 3589) Massive type, liver cancer arising in the right lobe with tumor thrombus of the portal vein. Liver weighing $2380 \mathrm{~g}$ in a 62 year-old man. $\alpha$ fetoprotein (+)

Photo 3. (No.3659) Diffuse type liver cancer and Miyake's B type liver cirrhosis. Liver weighing $1470 \mathrm{~g}$ in a 47 year-old man. $\alpha$ fetoprotein $(+)$

Photo 4. (No. 2647) Pipe-stem fibrosis due to schistosomiasis japonica and Miyake's B type liver cirrhosis with nodular liver cancer. Pseudolobules, nodular hyperplasia and small tumor can be observed. (Van-Gieson stain)

Photo 5. Trabecular liver cell carcinoma.

Photo 6. Trabecular liver cell carcinoma. The trabeculae are markedly covered by epithelium.

Photo 7. Trabecular liver cell carcinoma with fatty degeneration.
Photo 8. Trabecular liver cell carcinoma with schistosomiasis japonica. Calcified eggs of Schistosoma japonicum are seen in the connective tissue.

Photo 9. Trabecular liver cell carcinoma with clear cytoplasm and tiny canaliculi.

Photo 10. Miyake's B type liver cirrhosis. (Azan stain)

Photo 11. Trabecular liver cell carcinoma with giant cells, which may be caused by degeneration of tumor cells.

Photo 12. Immature giant cell carcinoma. Multinucleated and irregular shaped giant cells are seen in tumor cells showing loose arrangement.

Photo 13. Medular liver cell carcinoma without epithelium and canaliculi.

Photo 14. Glandular pattern in a trabecular liver cell carcinoma.

Photo 15. Bile duct carcinoma with moderate amount of fibrous stroma.

Photo 16. Bile duct carcinoma with schistosomiasis japonica. Many calcified eggs scattered in proliferated stroma. 


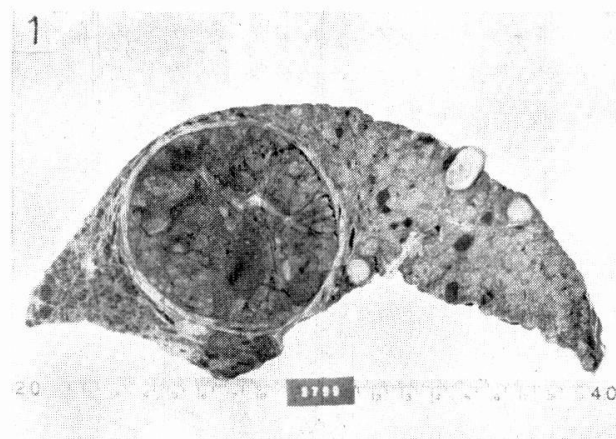

50.

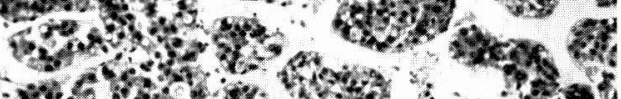

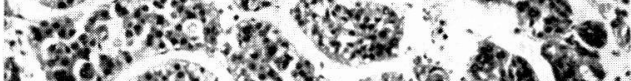
5.6.

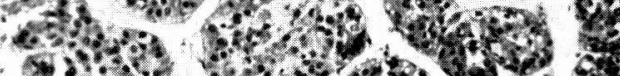
and

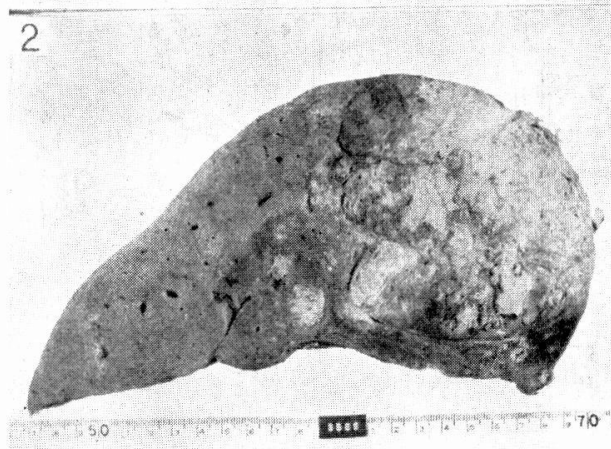

3

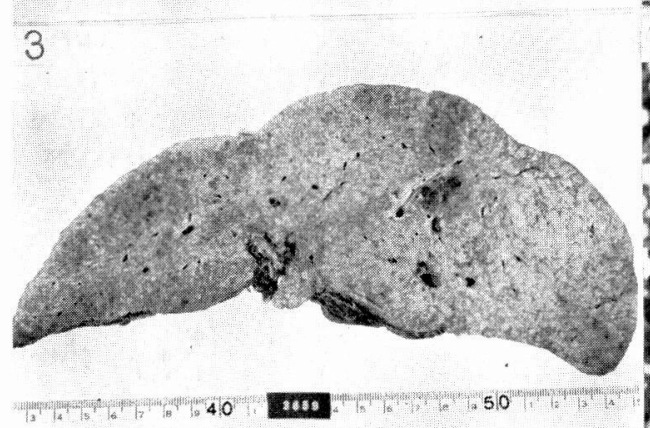

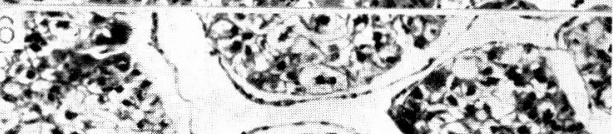

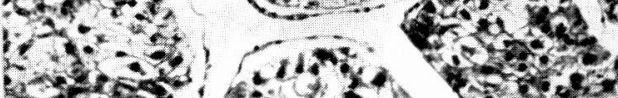

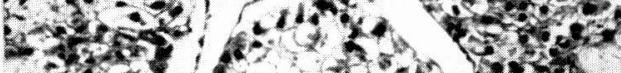

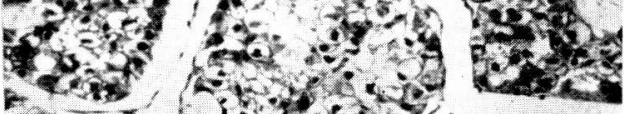

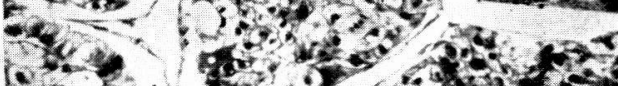

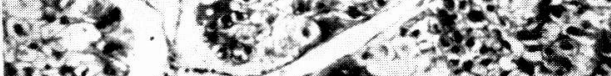

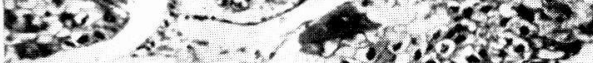

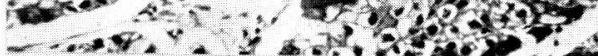

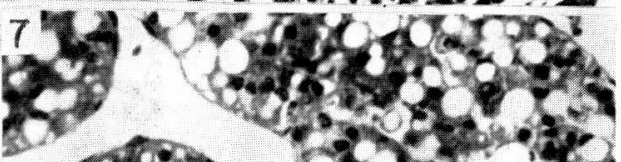

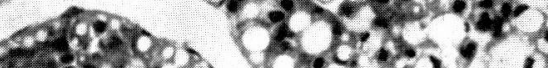

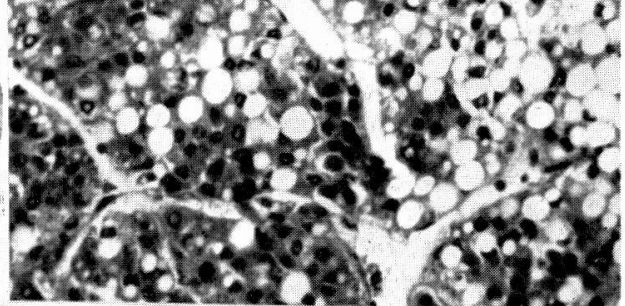
4 8 3.

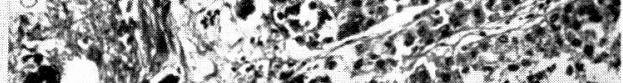

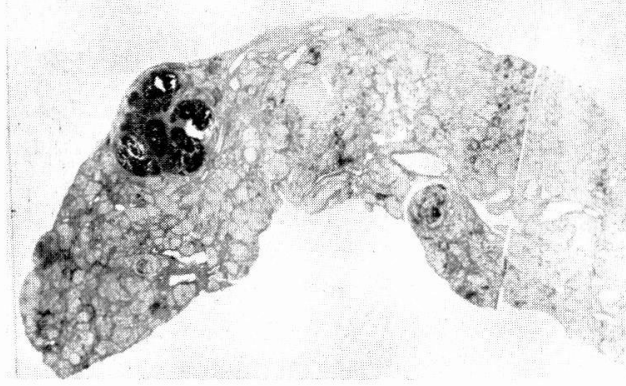
3. 


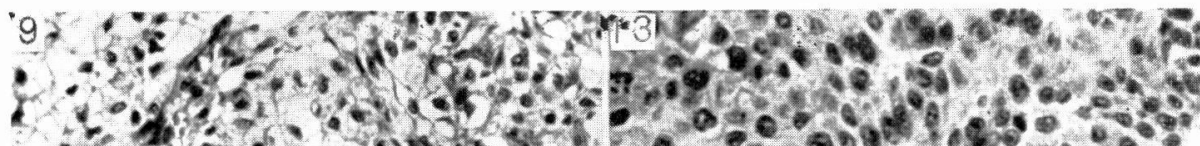
- Yv e r

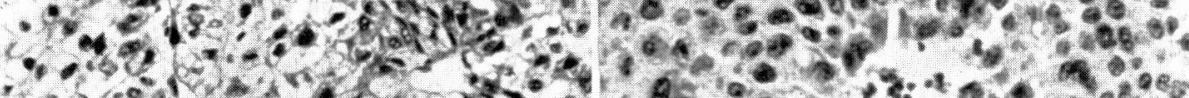

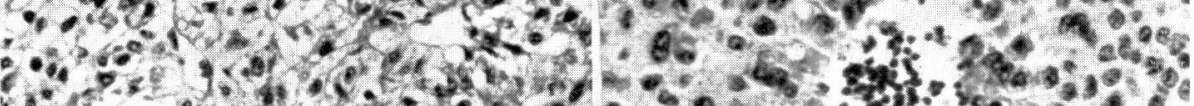

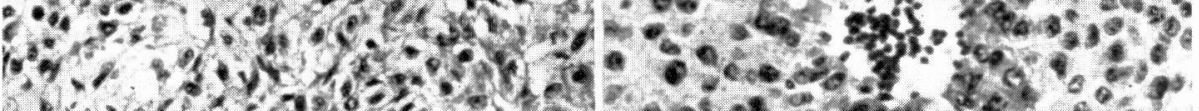

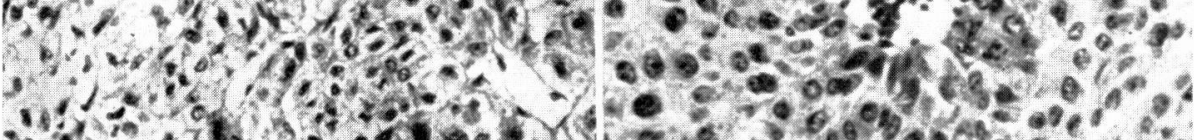
*1. 10 . E.

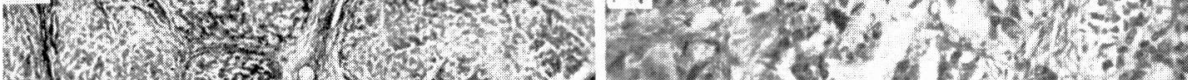

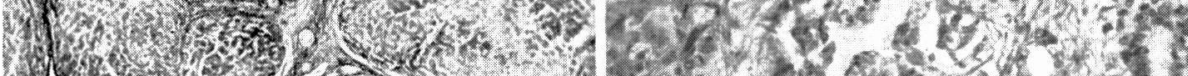

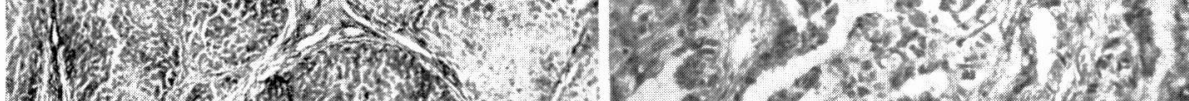

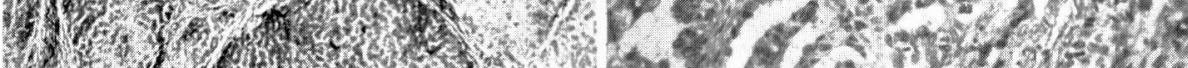
2. + a

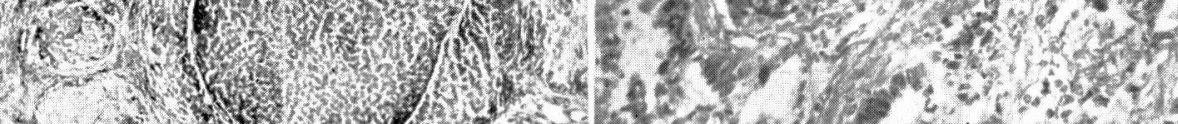

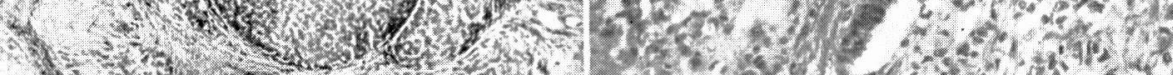

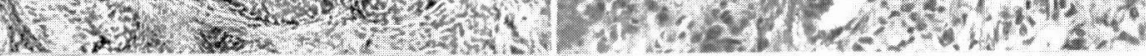

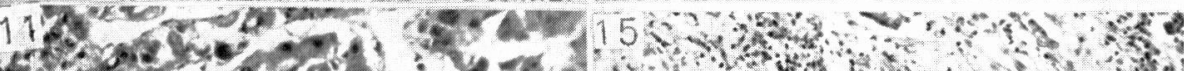

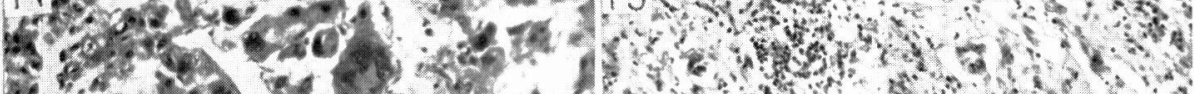

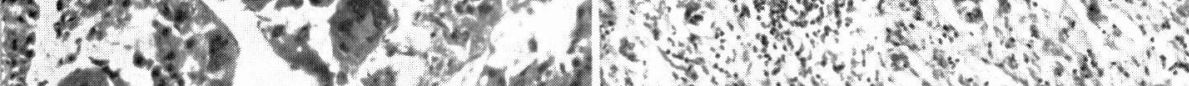

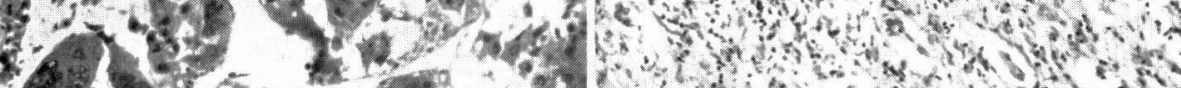

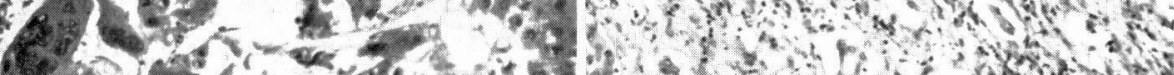

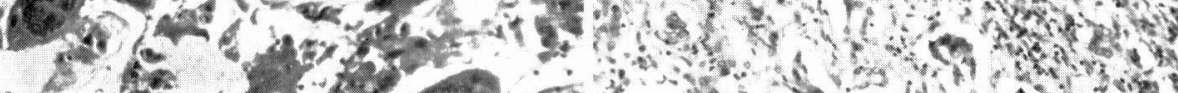

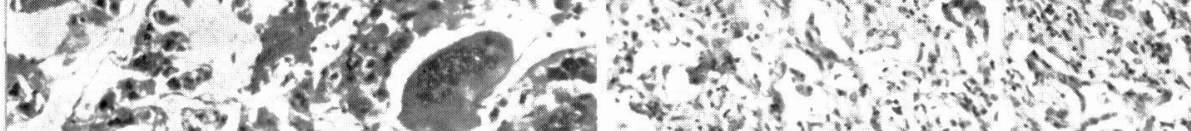

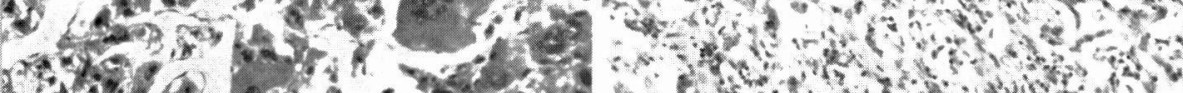

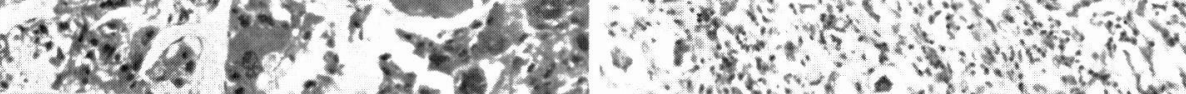

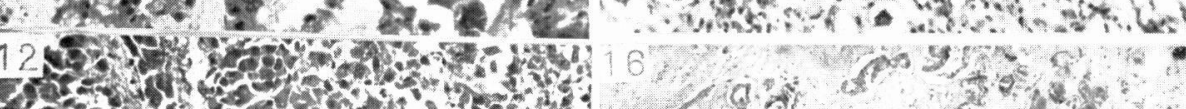

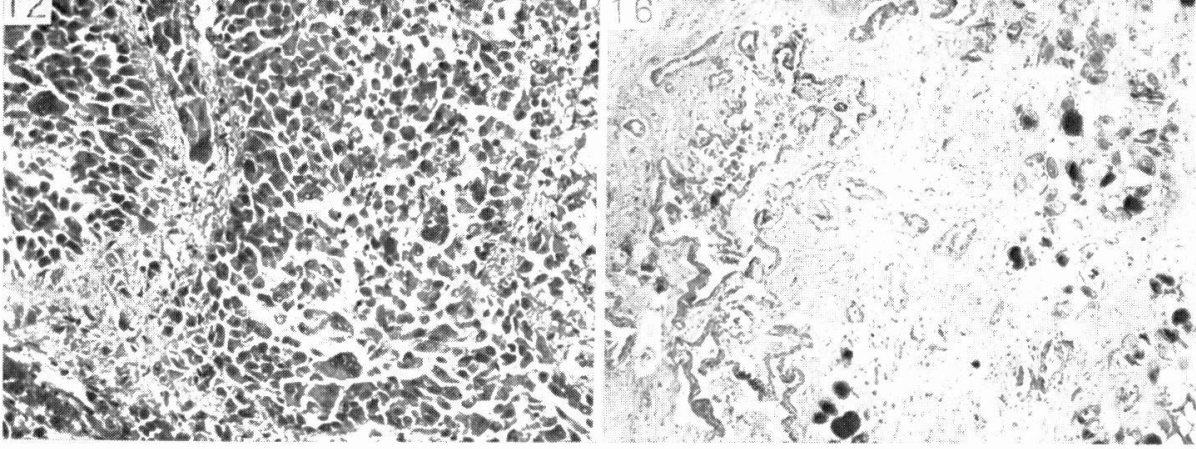

